\title{
PROPOSTA DE UM SENSOR OPTOELETRÔNICO PARA ANÁLISE DE MARCHA
}

\author{
Eric Augusto Ruebenich de Quadros ${ }^{1}$, Anderson Antônio Giacomolli ${ }^{2}$
}

Resumo: O termo "análise de marcha" é tema de várias pesquisas e artigos científicos. Os trabalhos abordam diferentes áreas, como esporte, saúde, identificação humana, monitoramento de postura entre outras aplicações. É possível analisar a marcha humana utilizando diversos tipos de sensores, dependendo das características da marcha que precisam ser analisadas. Dentre os mais relevantes, é possível citar eletrodos de eletromiografia, goniômetro, sensores inerciais, sensores de força, sensores ultrassônicos, sistema de monitoramento eletromagnético e tecidos sensíveis. Levando em consideração estes aspectos, o objetivo deste trabalho é fazer uma introdução ao tema com enfoque na análise da pressão plantar, que é o monitoramento das forças de reação do solo. Após a apresentação das diferentes maneiras de monitorar a pressão plantar, este trabalho enfoca na utilização de sensores optoeletrônicos e tem como objetivo propor o desenvolvimento de um sensor com um custo inferior às soluções disponíveis no mercado.

Palavras-chave: Sensores. Saúde. Eletrônica. Marcha. Pressão.

\section{INTRODUÇÃO}

A análise de marcha faz parte do estudo da locomoção humana e vem sendo utilizada com grande frequência no ramo de esportes e na saúde (RAZAK et al., 2012). Nos esportes, o objetivo principal é analisar a performance dos atletas e encontrar falhas, corrigindo-as antes das competições. Na saúde, é utilizada para acompanhamento de pessoas com osteoporose, doença de Parkinson ou monitorar pacientes em recuperação após alguma cirurgia.

Além destas áreas, estudos recentes abordam a utilização da análise de marcha para identificação humana e monitoramento de postura (RAZAK et al., 2012). Nesta análise, vários tipos de sensores podem ser fixados em diferentes partes do corpo, como pés e cintura. Estes sensores podem ser eletrodos de

1 Acadêmico do curso de Engenharia de Controle e Automação.

2 Mestre, docente e coordenador do curso de Engenharia de Controle e Automação. 
eletromiografia, goniômetro, sensores inerciais, sensores de força, sensores ultrassônicos, sistema de monitoramento eletromagnético e tecidos sensíveis (TAO et al., 2012; MURO-DE-LA-HERRAN et al., 2014). A análise possibilita monitorar vários parâmetros da marcha, tais como velocidade, comprimento e tempo do passo curto (distância linear entre dois estágios sucessivos do mesmo pé), comprimento e tempo do passo longo (distância linear entre os posicionamentos de ambos os pés), cadência ou ritmo (número de passos por unidade de tempo), tempo de suporte (momento em que o calcanhar toca o chão até que os dedos são levantadas, para cada pé), existência de tremores ao caminhar, registro de quedas, fases da marcha e as forças de reação do solo (FRS) (MURO-DE-LA-HERRAN et al., 2014).

Tendo em vista a importância do monitoramento e análise de marcha, este trabalho tem por objetivo a pesquisa e proposta de um sensor táctil para medição da pressão plantar. Para este tipo de medição existem três tipos de soluções que podem ser utilizadas: plataformas de força, baropodômetros e dispositivos dentro de calçados. As plataformas de força são dispositivos confiáveis e precisos, pois possuem sensores com sensibilidade de até $1 \mathrm{uN}$ e frequência de amostragem que pode chegar a $200 \mathrm{~Hz}$. Os baropodômetros possuem uma alta precisão espacial, que pode chegar a $1 \mathrm{~mm}$. No entanto estes dois tipos de dispositivos são afetados por várias limitações que restringem seu uso a laboratórios clínicos ou de pesquisas, tais como valores altos e falta de portabilidade. Além disso, as plataformas de força são afetadas pelo "efeito alvo", devido ao qual uma pessoa que está sendo avaliada pode mudar sua maneira de andar ao estar em cima dos sensores, pois sabe que está sendo monitorada (CREA et al., 2014).

Os dispositivos dentro de calçados são flexíveis, portáteis e de baixo custo em relação às plataformas e baropodômetros. E os novos estudos nesta área estão buscando dispositivos mais pequenos, leves e com melhor eficiência energética (RAZAK et al., 2012). Entretanto seu uso está limitado ainda a aplicações nas quais os resultados esperados não necessariamente devem ser precisos (CREA et al., 2014).

Nos últimos anos, diferentes tecnologias estão sendo desenvolvidas e comercializadas para a análise da pressão plantar utilizando dispositivos dentro de calçados. Alguns deles são a solução Pedar®, da Novel, que possui 99 sensores capacitivos de 1,9 mm de altura e pressão máxima de $1.200 \mathrm{kPa}$, e a F-Scan ${ }^{\circledR}$, da Tekscan, que possui 960 sensores resistivos de $0,15 \mathrm{~mm}$ de altura e pressão máxima de $1.034 \mathrm{kPa}$ (RAZAK et al., 2012).

O sensor estudado e proposto neste trabalho utiliza o princípio optoelétrico de maneira semelhante aos apresentados nos trabalhos de De Maria et al. (2012) (sensor táctil) e Crea et al. (2014) (sensor para análise de marcha). Os dois trabalhos utilizam um LED (Light-Emitting Diode) e um receptor de luz, um ao lado do outro dispostos em uma placa de circuito impresso, com um fechamento ao redor e um vão acima (FIGURA 1). O princípio de medição 
analisa a saída de tensão do receptor, sendo proporcional à luz emitida no vão que deforma de acordo com a pressão a qual a estrutura é submetida.

Figura 1 - Sensor optoeletrônico desenvolvido por Crea et al. (2014)

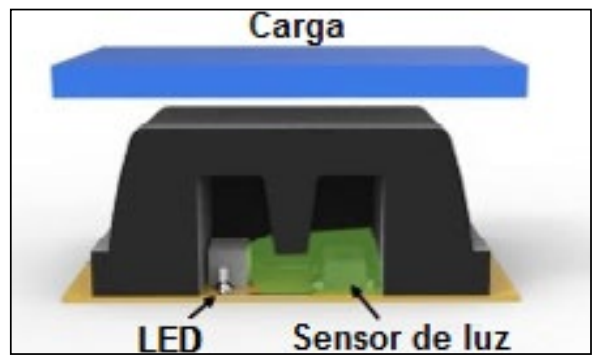

Fonte: adaptado pelos autores com base em Crea et al. (2014).

Buscando a diminuição de custos no desenvolvimento do sensor, optouse por propor um sensor utilizando LDRs (Light Dependant Resistors) e LEDs, baseado no estudo de Mohammed et al. (2013), mantendo o emissor ao lado do receptor. A solução adotada teve como principal fator o elevado custo e dificuldade de compras no Brasil dos componentes utilizados para reprodução dos experimentos apresentados nos dois artigos anteriormente citados.

Este artigo está dividido da seguinte forma: no segundo item são apresentados conceitos gerais sobre sensores tácteis, além da utilização de sensores para análise de marcha, sensores de pressão plantar e aplicações da análise de marcha; o terceiro item trata da descrição da proposta, apresentando o resultado esperado após o desenvolvimento do sensor; a seção de resultados e discussões, quarto item, apresenta os testes que foram feitos para mostrar o efeito presente na proposta; e quinto item aborda as considerações finais e traz uma conclusão parcial dos resultados obtidos até o momento.

\section{REVISÃO}

\subsection{Sensores tácteis}

Um dos primeiros trabalhos acadêmicos sobre sensores tácteis foi publicado por Leon D. Harmon em 1982. O estudo foi baseado em uma pesquisa realizada com 47 pessoas, das quais 17 eram pesquisadores acadêmicos, 20 eram fabricantes de equipamentos que utilizavam sensores tácteis, quatro eram consultores de pesquisa, dois eram usuários, dois pesquisadores do governo, um pesquisador de uma sociedade profissional e um pesquisador particular. Em seu artigo, Harmon ${ }^{7}$ definiu sensores tácteis como sendo sensores de força utilizados em formato de matriz para uma avaliação contínua da distribuição de forças sobre uma superfície, tendo como principal utilidade fornecer a robôs e outros tipos de máquinas a mesma capacidade de sentir que a pele fornece 
aos seres humanos. O autor definiu, por meio das entrevistas, critérios a serem seguidos durante o projeto dos sensores tácteis utilizados na área de robótica:

- a superfície de contato deve ser uniforme e durável;

- deve ser de baixo custo e de baixo consumo de energia;

- deve ser desenvolvido com o mínimo de fios e cabos possível;

- o sensor táctil precisa ser fino e flexível;

- o espaçamento entre os sensores de força da matriz deve ser de 1 a 2 $\mathrm{mm}$;

- é necessário haver entre 50 e 200 sensores por matriz;

- a sensibilidade mínima de peso deve ser de $1 \mathrm{~g}$ e o peso máximo suportado por cada sensor deve ser de $1 \mathrm{~kg}$;

- a saída deve ser estável, não necessariamente linear e com uma boa repetibilidade;

- a frequência de resposta do sensor deve ser em torno de $100 \mathrm{~Hz}$;

- a histerese deve ser baixa.

Harmon também citou outras aplicações para os sensores tácteis, sendo uma delas o uso para análise de marcha através do monitoramento de pontos de pressão dos pés durante a caminhada. Como complemento ao estudo de Harmon, em 2012, Razak et al. reuniu em seu artigo uma coletânea de informações de outros artigos e estabeleceu critérios específicos que preferencialmente devem ser seguidos pelos sensores tácteis quando o objetivo passa a ser a análise de marcha. Alguns critérios são iguais aos de Harmon, tais como baixo custo, baixo consumo de energia, mínimo de fios e cabos possível, espessura, flexibilidade, saída estável e com baixa histerese, mas outros são diferentes. A lista a seguir apresenta os principais critérios, diferentes de Harmon, e os referentes estudos, apontados no trabalho de Razak et al.:

- a massa total do sensor não deve ser superior a $300 \mathrm{~g}$ para que a caminhada não seja afetada significantemente (TANWAR et al., 2007);

- é preferível que o sinal seja linear, para tornar o seu condicionamento mais simples (FERGUSON-PELL et al., 1976);

- precisa apresentar baixa sensibilidade à variação de temperatura no intervalo de $20^{\circ} \mathrm{C}$ até $37^{\circ} \mathrm{C}$ (temperatura média do corpo humano), caso contrário uma compensação será necessária (FERGUSON-PELL et al., 1976);

- as dimensões de cada sensor de força não devem ser inferiores a $5 \times 5$ mm (RAZAK et al., 2012); 
- a frequência de resposta do sensor deve ser de no mínimo $200 \mathrm{~Hz}$ a fim de tornar possível o registro da marcha de praticamente todas atividades diárias (URRY, 1999);

- a pressão máxima suportada por cada sensor de força deve ser maior que 2,3 $\mathrm{MPa}$, o equivalente à uma pessoa saudável de $75 \mathrm{~kg}$ se equilibrando na ponta de um único pé (LUO et al., 1998);

No mínimo 15 sensores de força devem ser utilizados no sensor táctil para análise de marcha, cobrindo as 15 áreas que suportam a maioria do peso de uma pessoa e são responsáveis pelos ajustes de balanço do corpo. A Figura 2 ilustra estas áreas, sendo três no calcanhar, duas no meio do pé, cinco no metatarso e cinco nos dedos (SHU et al., 2010).

Figura 2 - Áreas anatômicas do pé

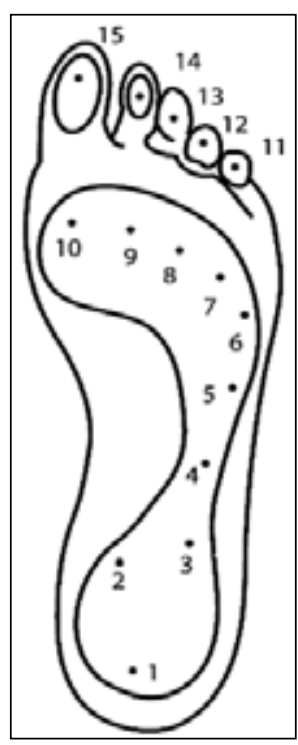

Fonte: Shu et al. (2010).

\subsection{Tipos de sensores utilizados para análise de marcha}

Vários tipos diferentes de sensores podem ser utilizados para análise de marcha, de forma individual ou em conjunto com outros, dependendo de qual característica será avaliada.

\subsubsection{Eletromiografia}

A eletromiografia pode ser utilizada na análise de marcha para analisar a pressão, movimento e velocidade dos pés. Ela consiste na aquisição do sinal elétrico proveniente de uma contração muscular, que pode ser obtido 
de forma não invasiva, utilizando eletrodos de superfície (FIGURA 3), ou invasiva, utilizando eletrodos do tipo fio ou agulha. A medição e o registro são complicados, pois a tensão de interesse está no intervalo de $0,01 \mathrm{mV}$ até 5 $\mathrm{mV}$, necessitando ser amplificado várias vezes (MURO-DE-LA-HERRAN et al., 2014).

Figura 3 - Sistema Brainquiry Wireless EMG/EEG/ECG

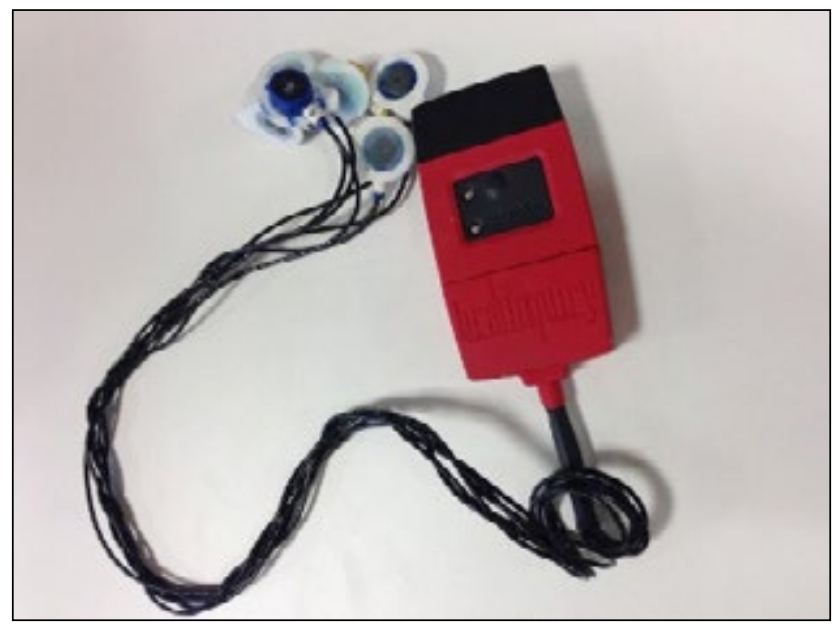

Fonte: Muro-de-la-Herran et al. (2014).

\subsubsection{Goniômetro}

Os goniômetros são usados para estudar os ângulos dos tornozelos, joelhos, quadris e metatarsos. Os mais comuns são os goniômetros flexíveis feitos com extensômetros (FIGURA 4). Eles variam sua resistência de acordo com a flexão do sensor, ou seja, de acordo com a mudança de ângulo das partes do corpo que estão sendo analisadas (MURO-DE-LA-HERRAN et al., 2014).

Figura 4 - Goniômetro flexível

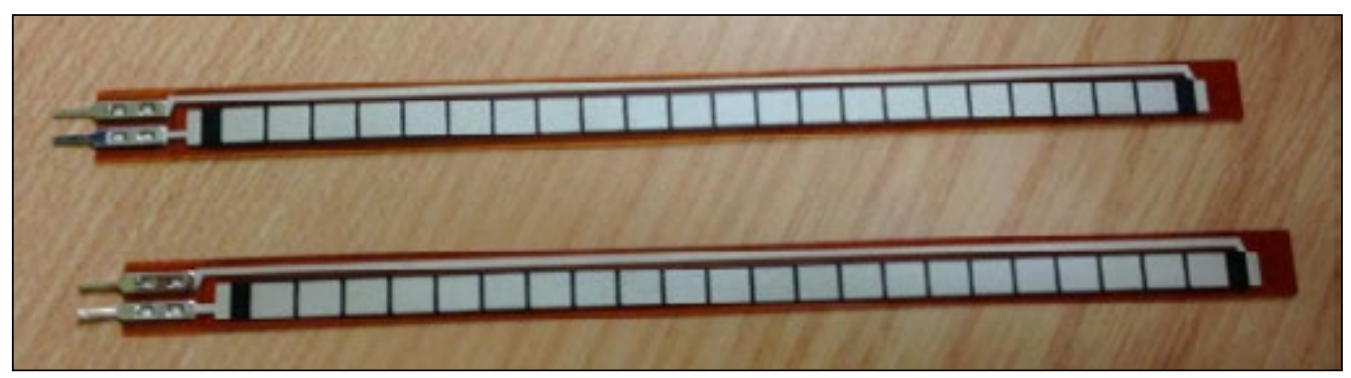

Fonte: Muro-de-la-Herran et al. (2014). 


\subsubsection{Sensores inerciais}

A utilização de sensores inerciais permite que sejam monitoradas a velocidade, aceleração e orientação de uma pessoa durante a análise de marcha utilizando uma combinação de acelerômetros, giroscópios e, às vezes, magnetômetros. O primeiro tipo mede a força inercial de um corpo de prova com massa conhecida e, através da segunda lei de Newton, calcula a aceleração ao longo de um eixo. Integrando a força inercial, é possível obter a velocidade, que, novamente integrada, resulta na posição em cada eixo. Com a posição em cada eixo, pode-se calcular a velocidade angular, que integrada, resulta no ângulo de flexão. O segundo tipo de sensor mensura os ângulos dos movimentos utilizando o efeito Coriolis, que é proporcional à força contrária ao movimento rotativo de uma parte mecânica localizada dentro do componente. Já o terceiro mede a orientação do corpo tendo como base a força gravitacional da Terra (MURO-DE-LA-HERRAN et al., 2014).

\subsubsection{Sensores de força}

Os sensores de força podem ser embutidos dentro de calçados para realizar medições da força de reação do solo. Essa força é um vetor tridimensional com direção que depende da maneira que ocorre o contato do pé com o solo (TAO et al., 2012). A seguir são apresentados os principais tipos de sensores de força.

\subsubsection{Sensores ultrassônicos}

Utilizando sensores ultrassônicos é possível analisar a distância entre os dois pés e a distância entre cada um dos pés e o chão. O princípio de funcionamento consiste na emissão de ondas sonoras e na medição do tempo de resposta do sinal. A distância é calculada levando em consideração o tempo obtido e a velocidade do som (MURO-DE-LA-HERRAN et al., 2014).

\subsubsection{Sistema de monitoramento eletromagnético}

O sistema de monitoramento eletromagnético é um dispositivo de mapeamento 3D que utiliza os princípios da lei de indução magnética de Faraday. $\mathrm{O}$ sistema consiste em um ambiente com campo magnético controlado e bobinas colocadas nas partes do corpo que serão analisadas. A tensão induzida nas bobinas é alterada conforme a mudança de posição ou orientação em relação ao campo magnético externo, sendo este o sinal pelo qual a marcha é analisada (TAO et al., 2012).

\subsubsection{Tecido sensível}

Os tecidos sensíveis são combinações de tecidos normais com elementos sensores, que podem ser colocados apenas superficialmente ou até substituir 
algumas fibras de tecidos. Os elementos sensores mais utilizados para este fim possuem princípios piezoelétricos, piezoresistivos ou piezocapacitivos. Em comparação a outros tipos de sensores, os tecidos sensíveis são mais flexíveis e leves para a medição da postura e movimento (TAO et al., 2012).

\subsection{Sensores de força}

Vários tipos de sensores podem ser utilizados para medir a força de reação do solo, alguns tipos são os capacitivos, piezoelétricos, piezoresistivos, resistivos e optoeletrônicos, que são apresentados na sequência.

\subsubsection{Capacitivos}

Os sensores capacitivos consistem em duas placas condutivas eletricamente carregadas separadas por uma camada elástica dielétrica que varia sua espessura conforme a pressão colocada sobre o sensor e, por consequência, varia sua capacitância (RAZAK et al., 2012).

Lei et al. (2012) utilizou duas placas de circuito impresso flexíveis, separadas por polidimetilsiloxano, como material dielétrico e uma camada de impacto composta por meia esferas, também de polidimetilsiloxano, para pressionar a camada superior de acordo com a força sobre ela (FIGURA 5).

Figura 5 - Sensor capacitivo desenvolvido por Lei et al. (2012)

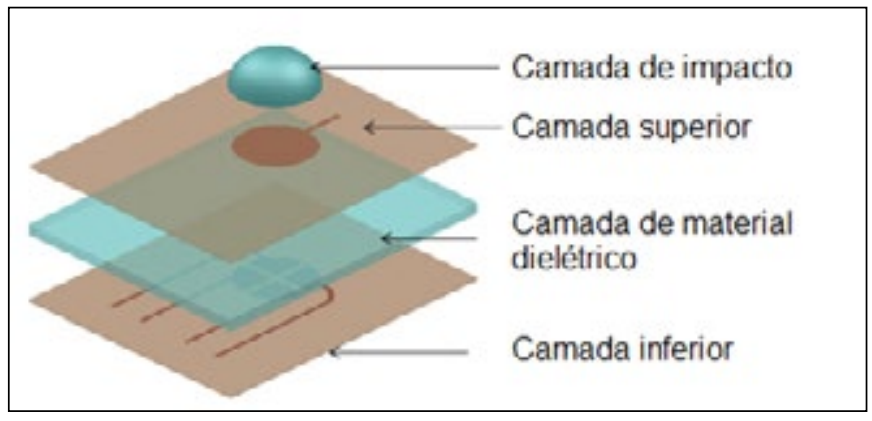

Fonte: adaptado pelos autores com base em Lei et al. (2012).

\subsubsection{Piezoelétricos}

Os sensores piezoelétricos produzem um campo elétrico em resposta à pressão a qual está sujeito. Este tipo de dispositivo possui uma alta impedância de saída e é suscetível a interferências elétricas que geram ruídos durante as medições (RAZAK et al., 2012).

Krishna et al. (2004) desenvolveu uma matriz de sensores piezoelétricos utilizando um círculo de titanato zirconato de chumbo (PZT) com $1 \mathrm{~mm}$ de 
espessura e $20 \mathrm{~mm}$ diâmetro composto por eletrodos na parte superior e inferior. Estes eletrodos são selecionados através de dois multiplexadores analógicos e excitados com uma frequência de $1 \mathrm{MHz}$ para diminuir o ruído característico deste tipo de sensor (FIGURA 6).

Figura 6 - Diagrama do sensor piezoelétrico montado por Krishna et al. (2004)

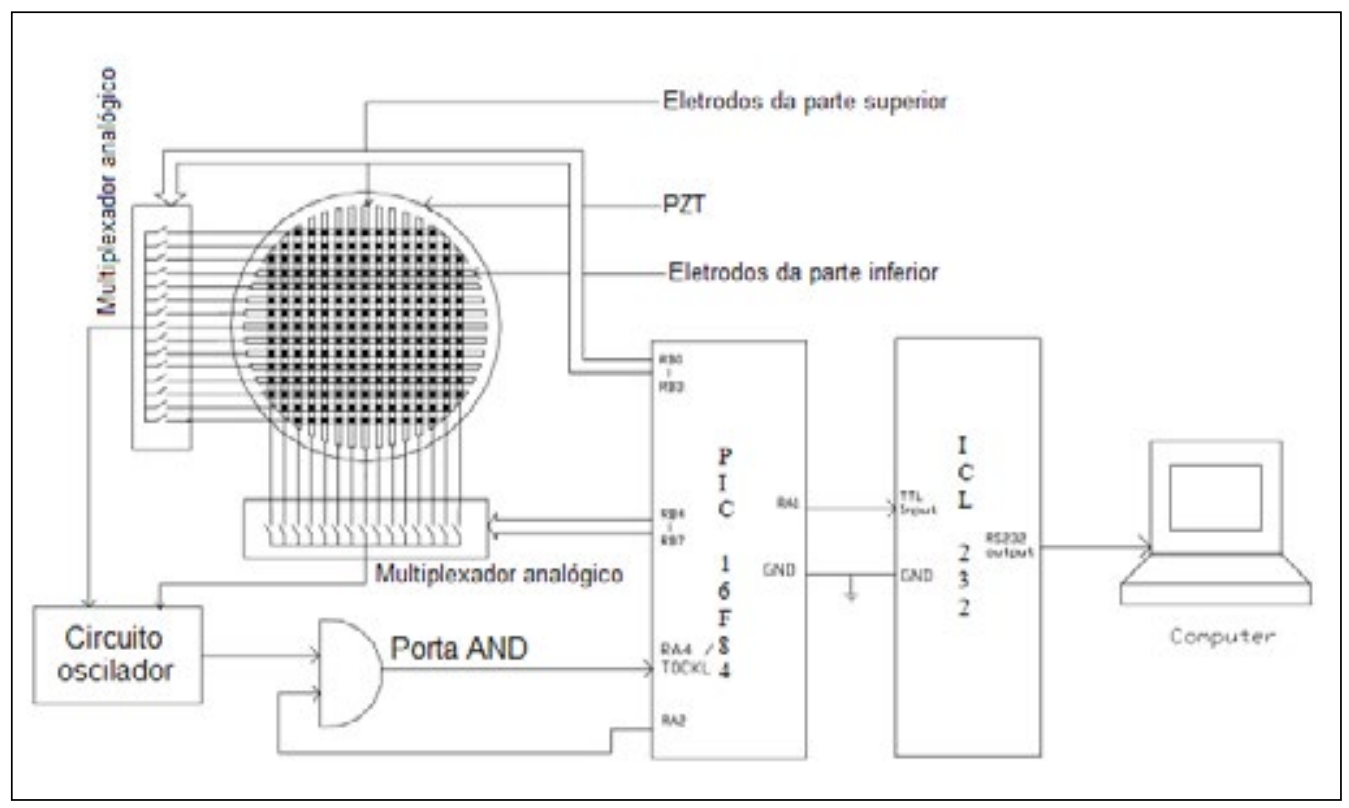

Fonte: adaptado pelos autores com base em Krishna et al. (2004).

\subsubsection{Piezoresistivos}

Razak et al. (2012) define sensor piezoresistivo como sendo um material semicondutor que tem sua resistência elétrica variável conforme a pressão ou força aplicada sobre ele. Quando é pressionado, a resistência aumenta, diminuindo à medida que a pressão é retirada.

Utilizando o princípio dos sensores piezoresistivos, Jung et al. (2015) desenvolveu um sensor táctil composto de vários sensores de pressão, formados por um elemento piezoresistivo de nanotubos de carbono e blocos de polímero condutivo ao redor (FIGURA 7). À medida que estes se movimentam ou têm a espessura variada, é gerada uma resistência em relação ao bloco central de nanotubos de carbono. 
Figura 7 - Sensor piezoresistivo desenvolvido por Jung et al. (2015)

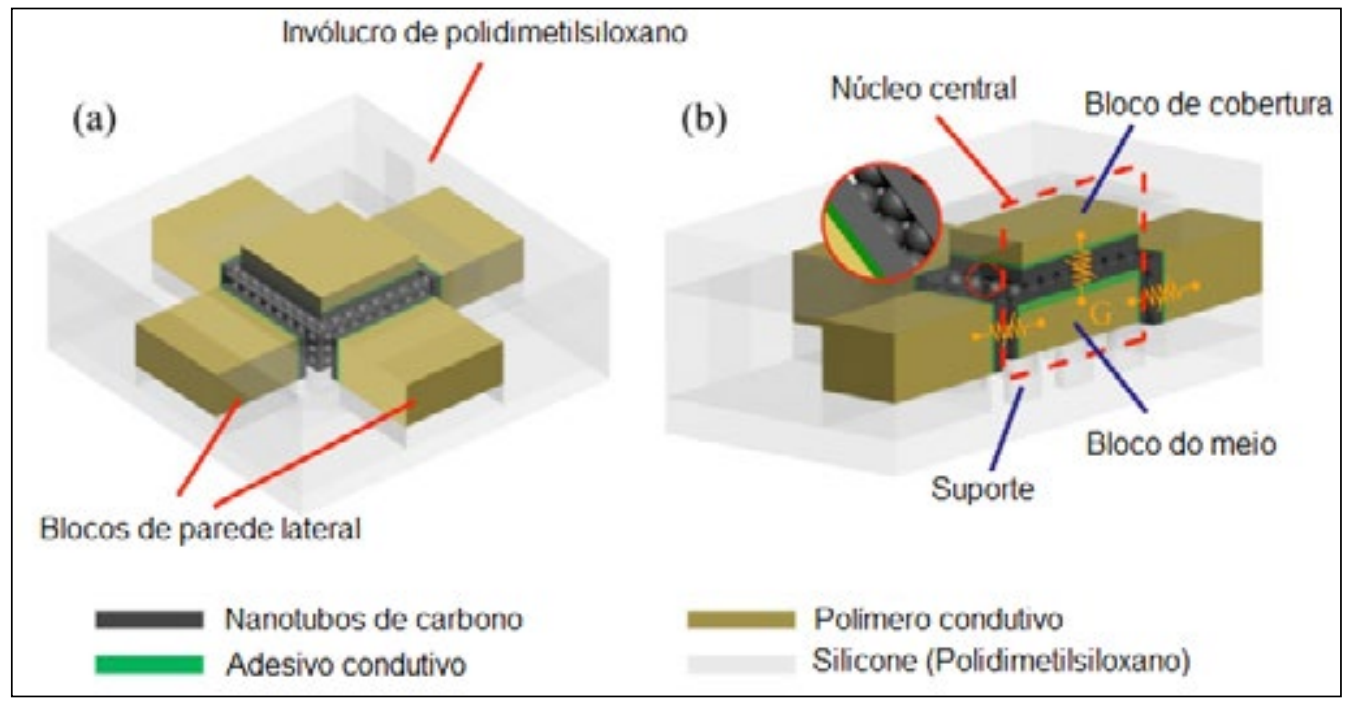

Fonte: adaptado pelos autores com base em Jung et al. (2015).

\subsubsection{Resistivos}

Sensores resistivos são feitos com um polímero, disposto entre dois eletrodos, que muda sua resistência de acordo com a pressão. A corrente elétrica que circula entre um eletrodo e outro aumenta à medida que o polímero muda sua espessura, ou seja, a resistência é alterada (RAZAK, et al., 2012).

Em 2015, González et al. utilizou quatro sensores comerciais de força resistivos acoplados na palmilha de um calçado (FIGURA 8) em conjunto com sensores inerciais para monitorar e identificar as fases da marcha humana. 
Figura 8 - Posicionamento dos sensores resistivos no dispositivo de González et al. (2015)

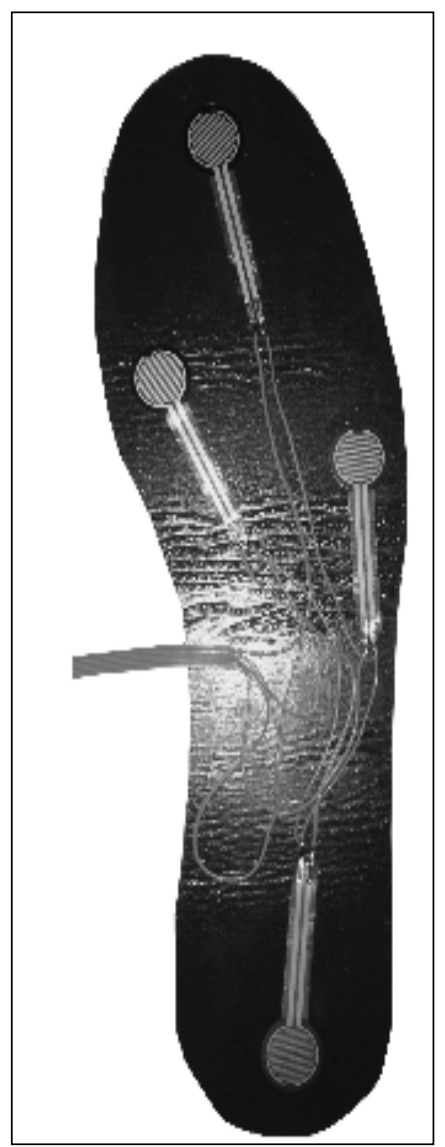

Fonte: González et al. (2015)

\subsubsection{Optoeletrônicos}

Sensores optoeletrônicos são formados por um emissor e um receptor de luz localizado dentro de um invólucro de material elástico. À medida que o material elástico é deformado pela pressão a que é exposto, a quantidade de luz do emissor recebida pelo receptor varia, sendo possível estimar a pressão (CREA et al., 2014).

De Maria et al. (2012) desenvolveu um sensor táctil para ser utilizado em robôs utilizando uma matriz de 16 sensores formados por um LED infravermelho, um fototransistor infravermelho, ambos da OSRAM, e uma capa de silicone preto (FIGURA 9). 
Figura 9 - Estrutura do sensor desenvolvido por De Maria et al. (2012)

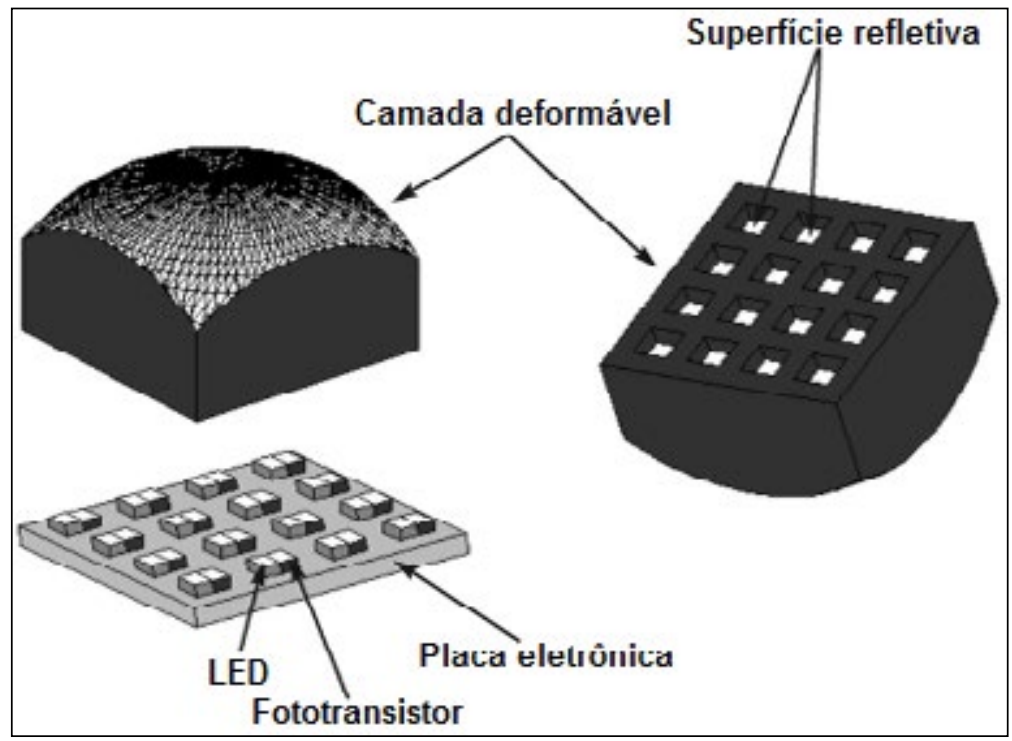

Fonte: adaptado pelos autores com base em De Maria et al. (2012).

Utilizando LEDs e LDRs, Mohammed et al. (2013) desenvolveu uma superfície que determina a distribuição do peso de uma pessoa em seus pés. Em seu projeto, foi utilizado sete conjuntos compostos por um LED e um LDR dispostos um de frente para o outro (FIGURA 10).

Figura 10 - Plataforma desenvolvida por Mohammed et al. (2013)

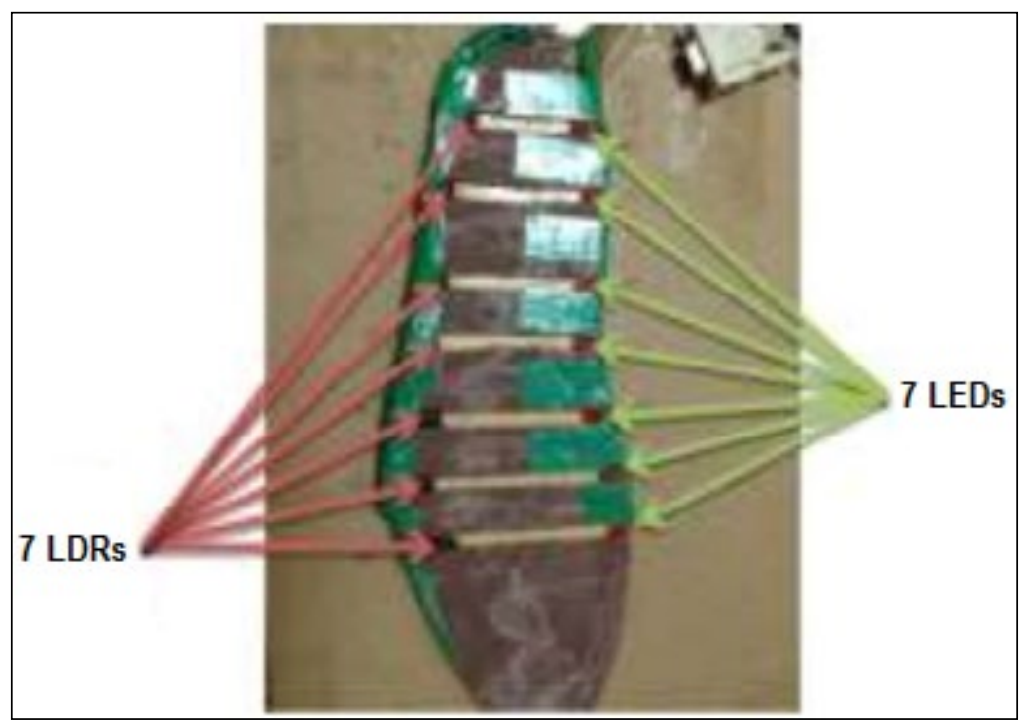

Fonte: adaptado pelos autores com base em Mohammed et al. (2013). 
Em 2014, Crea et. al. desenvolveu um sensor optoeletrônico formado por um sensor de luz da AVAGO, um LED verde da OSA Opto Light e uma capa de silicone preto, e acomodou 64 destes sensores, isolados um dos outros, em uma placa de circuito impresso no formato de um pé, com o objetivo de fazer análise de marcha (FIGURA 11).

Figura 11 - Dispositivo com 64 sensores optoeletrônicos de Crea et al. (2014), voltado para análise de marcha

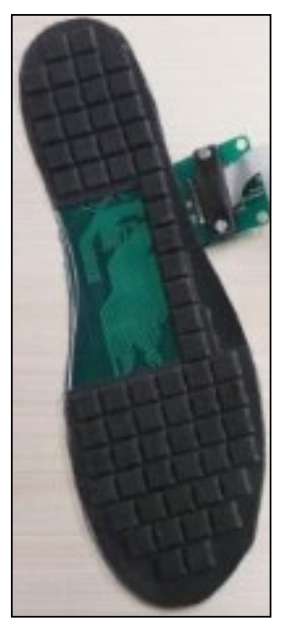

Fonte: adaptado pelos autores com base em Crea et al. (2014).

\subsection{Aplicações da análise de marcha}

Com o desenvolvimento de novas tecnologias de sensores e novas formas de aquisição e análise de dados, a análise de marcha tem sido utilizada em diversas aplicações, como as descritas a seguir.

\subsubsection{Esportes}

O desempenho de um atleta durante o treino pode ser monitorado com a utilização de sensores para análise de marcha. A análise visa melhorar a performance do atleta, levando em consideração que uma deficiência pode ser encontrada e corrigida antes das competições (TAO et al., 2012).

Ghasemzadeh et al. publicou, em 2011, dois artigos sobre o uso de sensores inerciais no monitoramento de atletas de golfe e de atletas de baseball, nos quais ele cita a análise de marcha como um parâmetro a ser avaliado para melhoramento de performance. Com o mesmo enfoque, também em 2011, Wahab et al. publicou um artigo sobre o uso de sensores ultrassônicos na análise de marcha de atletas durante corridas. 


\subsubsection{Identificação humana}

Edwards et al. (2014) publicou um artigo no qual são utilizados padrões de forças de reação do solo em relação a algumas pessoas para explorar a marcha como método de identificação humana. Para isso, contou com uma matriz de sensores piezoelétricos e um algoritmo de floresta aleatória treinada com um banco de dados de 10.413 padrões provenientes de 94 voluntários. Dentro deste banco de dados, a taxa de erro no momento da identificação foi de $16,3 \%$, mas ao final do estudo, Edwards sugere maneiras de diminuir este erro.

\subsubsection{Monitoramento da postura e atividades}

Sazonov et al. (2011) utilizou sensores inerciais em conjunto com cinco sensores de força resistivos com o objetivo de monitorar a postura e as atividades de pessoas. O monitoramento visava estimar a quantidade de energia gasta após cada atividade realizada.

\subsubsection{Reabilitação}

Na área de reabilitação, a análise de marcha é utilizada para monitorar pacientes com paralisia cerebral, doença de Parkinson e outras enfermidades. $\mathrm{O}$ objetivo do monitoramento é auxiliar na tomada de decisão antes de cirurgias e o acompanhamento de um tratamento ou recuperação pós-cirúrgica (TAO et al., 2012).

\section{DESCRIÇÃO DA PROPOSTA}

Atualmente há várias soluções no mercado nacional disponíveis para compra por profissionais que pretendem analisar a marcha, mas todas elas são importadas e se tornam caras, devido à taxa de câmbio e ao imposto de importação. Como exemplo, é possível citar os dispositivos de medição de pressão plantar da Novel. A plataforma Emed® é anunciada, no site da empresa, por $€ 18.450,00$ (NOVEL, 2016) e o dispositivo para uso em calçados Pedar ${ }^{\circledR}$ é anunciado por $€ 15.450,00$ (NOVEL, 2016). Supondo que um euro equivalha à quatro reais e o imposto de importação seja de $100 \%$, os preços passam a ser de $\mathrm{R} \$ 147.600,00$ e $\mathrm{R} \$ 123.600,00$, respectivamente.

A solução proposta neste trabalho é um sensor táctil de custo inferior às soluções atuais voltado para a análise de marcha, que pode ser acoplado em uma placa de aquisição de dados, também de custo inferior, aumentando o acesso de fisioterapeutas brasileiros a este tipo de dispositivo. O dispositivo será formado por um sensor táctil (matriz de sensores de pressão), multiplexadores, circuitos de condicionamento e amplificação de sinal, um filtro passa-baixas e uma placa de aquisição de dados. A Figura 12 ilustra as várias partes do dispositivo proposto neste trabalho. 
Figura 12 - Estrutura da solução proposta

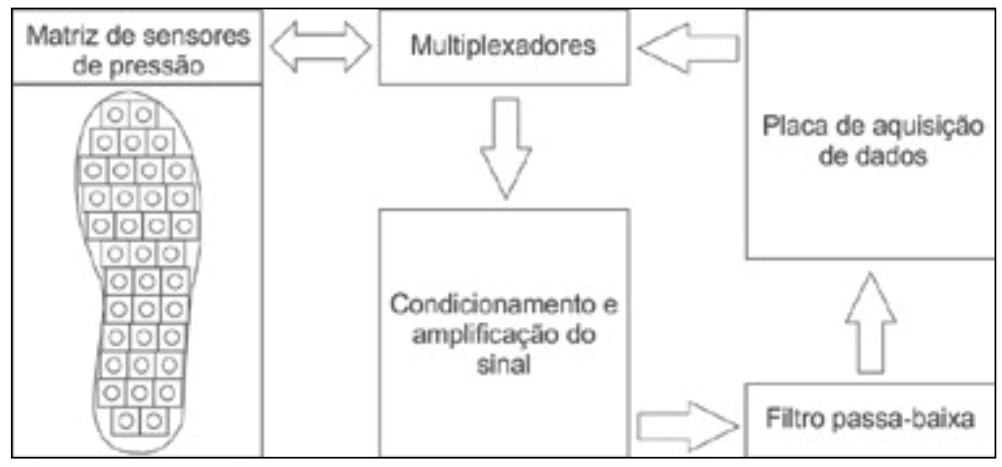

Fonte: dos autores.

Os sensores de pressão que formam a matriz do sensor táctil serão feitos com poliuretano (PU). O PU é um material leve, flexível, elástico, isolante térmico, durável, que não amolece com o calor e possui alta resistência à abrasão, flexão e rasgo (VILAR, 2004). Os dispositivos sensores serão semelhantes aos desenvolvidos por De Maria et al. (2012) e Crea et al. (2014). Possuindo uma cavidade no meio do material, o dispositivo abriga um LED e LDR. A deformação da estrutura do sensor é obtida pela medição da luz refletida conforme ilustrado na Figura 13.

Figura 13 - Sensor de pressão que formará a matriz

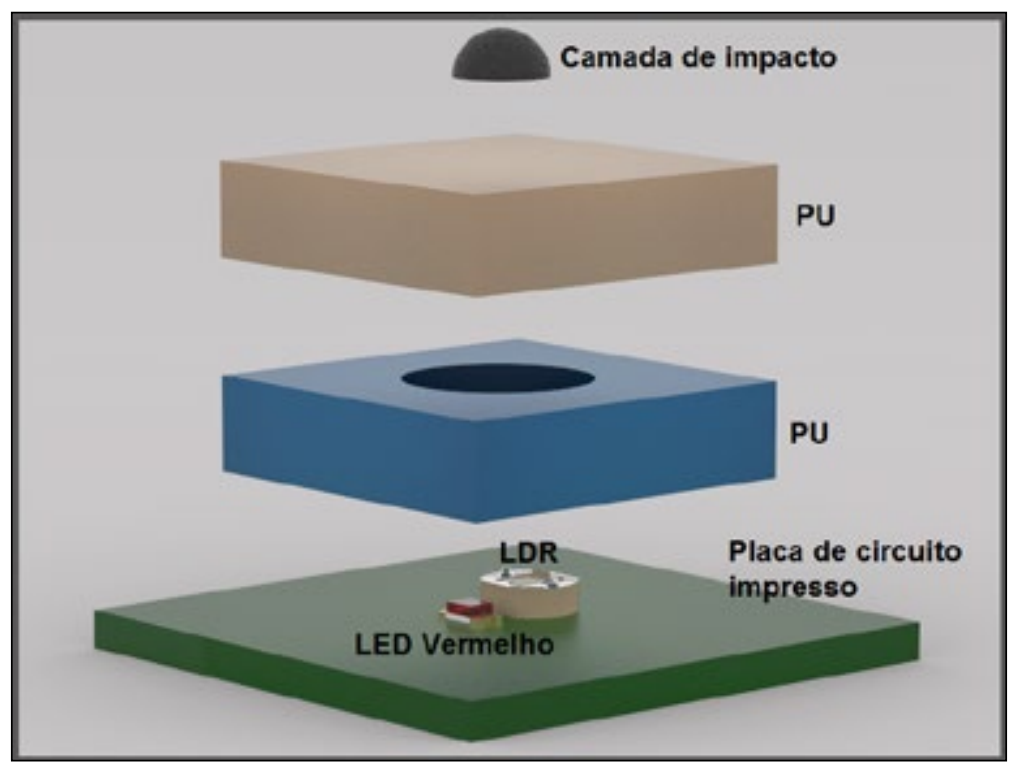

Fonte: dos autores. 
Na construção do sensor, optou-se por atender os critérios preferenciais que se referem a espessura, flexibilidade, massa, dimensões, pressão máxima e mínimo de sensores de pressão listados no trabalho de Razak et al. (2012). Seguindo essa abordagem, será necessário utilizar multiplexadores digitais e analógicos devido a utilização em forma de matriz. Os multiplexadores digitais são utilizados para escolher quais sensores de pressão terão seu sinal mensurado. Os multiplexadores analógicos possibilitam a utilização de um único circuito de condicionamento de sinal, amplificação e filtro para todos os sensores de luz.

Após a multiplexação, o sinal do sensor passará por uma etapa de condicionamento do sinal, sendo amplificado até a tensão desejada. Nesta etapa os critérios preferenciais de linearidade, histerese, sensibilidade à temperatura e estabilidade no sinal de saída listados por Razak et al. ${ }^{1}$ devem ser alcançados com o correto projeto do circuito.

Após a fase de condicionamento e amplificação, o sinal é filtrado em filtro passa-baixas, buscando atender o critério preferencial do Razak et al. (2012) que diz ser necessário analisar os sinais de até $200 \mathrm{~Hz}$.

O sinal, depois de filtrado, é capturado por uma placa de aquisição de dados com conversor analógico para digital (Analog-to-Digital converter - AD) e saídas digitais. $\mathrm{O}$ conversor $\mathrm{AD}$ será utilizado para aquisição dos dados com uma frequência de no mínimo $400 \mathrm{~Hz}$ (dobro da maior frequência do sinal). As saídas digitais ditam qual deverá o sensor do qual o sinal será medido através de seus pinos digitais e o multiplexador.

No projeto de todo o conjunto, será tentado atender ao restante dos critérios de Razak et al. (2012), que são baixo custo, baixo consumo de energia e mínimo de cabos possível.

\section{RESULTADOS E DISCUSSÕES}

Com o objetivo de analisar a resposta do sensor optoeletrônico isoladamente, foi utilizada prensa para ensaios de compressão da Contenco, modelo I-1006-FA, e um transdutor de pressão da Honywell, modelo BP344AV, que foi colocado acima da camada de impacto.

A aquisição dos sinais foi feita utilizando um conversor AD de 10 bits do Arduino UNO, referência de tensão analógica de 3,3 V e frequência de aquisição de $400 \mathrm{~Hz}$. Para a eliminação de ruídos que passaram pelo filtro passa-baixa, foi utilizado um filtro digital de média móvel com 30 amostras.

$O$ ensaio realizado foi uma sequência de três compressões e descompressões (FIGURA 14) para verificar a diferença de comportamento dos dois sensores quando expostos a uma mesma pressão. 
Figura 14 - Sequência de três ensaios de compressão e descompressão

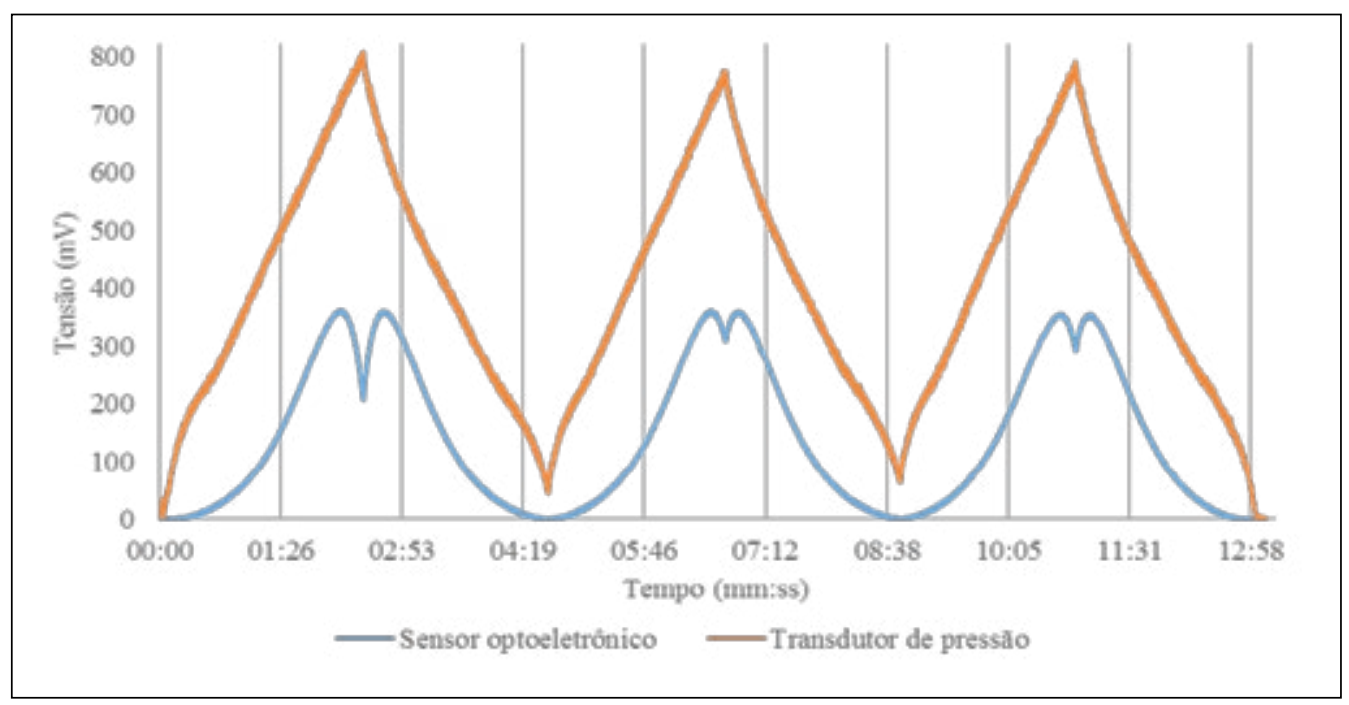

Fonte: dos autores.

A partir dos resultados apresentados acima é possível notar que o sensor proposto possui uma resposta proporcional à pressão a qual está sendo submetido. Então através da utilização de sensores iguais a estes conectados em forma de matriz é possível analisar todos os pontos dos pés durante a marcha.

A principal diferença entre a resposta do sensor optoeletrônico desenvolvido e o sensor de pressão comercial é que o optoeletrônico satura após determinada pressão, caso este efeito se repita ao utilizar vários sensores em forma de matriz, aumentando a superfície de contato, uma solução possível é a utilização de silicone transparente dentro do vão do sensor.

\section{CONSIDERAÇÕES FINAIS}

Inicialmente, antes de se optar pelo sensor de pressão optoeletrônico, foram efetuados testes com materiais piezoelétricos e diversos tipos de espumas antiestáticas. No primeiro método, procurou-se medir a tensão que era gerada pelos materiais, e, no segundo método, procurou-se uma espuma que variasse sua resistência conforme a pressão que incidia sobre ela.

Paralelamente a estes testes, um banco de artigos com 150 itens sobre sensores tácteis e análise de marcha foi montado. Deste total, em torno de 40 artigos foram sinalizados como úteis e divididos em categorias pelo seu assunto. E por fim, 22 foram escolhidos para formar a referência para este trabalho.

Sensores optoeletrônicos são uma opção de baixo custo para medição de força, pois os valores dos componentes envolvidos são baixos, sendo necessários LEDs e sensores de luz, tais como fotodiodos, fototransistores ou 
LDRs. Mas devido à dificuldade de localizar, no mercado brasileiro, sensores de luz pequenos, como os utilizados por De Maria et al. e Crea et al., optou-se por utilizar LDRs.

Devido às propostas apresentadas nesse trabalho é possível que seja desenvolvido um sistema completo móvel de análise de marcha com custo inferior às soluções disponíveis no mercado atualmente para que todos fisioterapeutas tenham este tipo de equipamento em seus consultórios, deixando de ser uma exclusividade de poucos profissionais e de laboratórios acadêmicos.

\section{REFERÊNCIAS}

CREA, Simona; DONATI, Marco; DE ROSSI, Stefano; ODDO, Calogero; VITIELLO, Nicola. A Wireless Flexible Sensorized Insole for Gait Analysis. Sensors, v. 14, n. 1, p. 1073 1093, 2014. Disponível em: <http://www.mdpi.com/1424 8220/14/1/1073/>. Acesso em: 16 mar. 2016.

DE MARIA, G.; NATALE, C.; PIROZZI, S. Force/tactile sensor for robotic application. Sensors and Actuators A: Physical, v. 175, p. 60 72, 2012. Disponível em: <http:/ / linkinghub.elsevier.com/retrieve/pii/S0924424711007564>. Acesso em: 16 mar. 2016.

EDWARDS, Michael; XIE, Xianghua. Footstep pressure signal analysis for human identification. 7th International Conference on Biomedical Engineering and Informatics, IEEE, 2014, p. 307 312. Disponível em: <http:/ /ieeexplore.ieee.org/ lpdocs/epic03/wrapper.htm?arnumber=7002790>. Acesso em: 16 mar. 2016.

FERGUSON PELL, M. W.; BELL, F.; EVANS, J. H. Interface Pressure Sensors: Existing Devices, Their Suitability And Limitations. Bed Sore Biomechanics, Macmillan Education UK, 1976, p. 189 197. Disponível em: <http://link.springer.com/ chapter/10.1007/978-1-349-02492-6_26>. Acesso em: 22 maio 2016.

GHASEMZADEH, Hassan; LOSEU, Vitali; GUENTERBERG, Eric; JAFARI, Roozbeh. Sport training using body sensor networks: a statistical approach to measure wrist rotation for golf swing. 4th International ICST Conference on Body Area Networks ICST, 2011. Disponível em: <http:/ / eudl.eu/doi/10.4108/ICST. BODYNETS2009.6035>. Acesso em: 27 maio 2016.

GHASEMZADEH, Hassan; JAFARI, Roozbeh. Coordination analysis of human movements with body sensor networks: A signal processing model to evaluate baseball swings. Sensors Journal, IEEE, v. 11, n. 3, p. 603 610, 2011. Disponível em: $<$ http:/ /ieeexplore.ieee.org/xpls/abs_all.jsp?arnumber=5482088>. Acesso em: 26 maio 2016.

GONZÁLEZ, Iván; FONTECHA, Jesús; HERVÁS, Ramón; BRAVO, José. An Ambulatory System for Gait Monitoring Based on Wireless Sensorized Insoles. Sensors, v. 15, n. 7, p. 16589 16613, 2015. Disponível em: <http:/ / www.mdpi. com/14248220/15/7/16589/>. Acesso em: 16 mar. 2016. 
HARMON, Leon D. Automated tactile sensing. The International Journal of Robotics Research, v. 1, n. 2, p. 3 32, 1982. Disponível em: <http:/ /ijr.sagepub.com/ content/1/2/3.short>. Acesso em: 30 mar. 2016.

JUNG, Youngdo; LEE, Duck Gyu; PARK, Jonghwa; KO, Hyunhyub; LIM, Hyuneui. Piezoresistive Tactile Sensor Discriminating Multidirectional Forces. Sensors, v. 15, n. 10, p. 25463 25473, 2015. Disponível em: <http://www.mdpi.com/1424 8220/15/10/25463/>. Acesso em: 16 mar. 2016.

KRISHNA, G. Murali; RAJANNA, K. Tactile sensor based on piezoelectric resonance. Sensors Journal, IEEE, v. 4, n. 5, p. 691 697, 2004. Disponível em: <http:/ / ieeexplore. ieee.org/xpls/abs_all.jsp?arnumber=1331377>. Acesso em: 24 mar. 2016.

LEI, Kin Fong; LEE, Kun Fei; LEE, Ming Yih. Development of a flexible PDMS capacitive pressure sensor for plantar pressure measurement. Microelectronic Engineering, v. 99, p. 1 5, 2012. Disponível em: <http:/ /linkinghub.elsevier.com/ retrieve/pii/S0167931712002663 >. Acesso em: 16 mar. 2016.

LUO, Zong Ping; BERGLUND, Lawrence. J.; AN, Kai Nan. Validation of F Scan pressure sensor system: a technical note. Journal of Rehabilitation Research and Development, v. 35, n. 2, p. 186 191, 1998. Disponível em: <http:/ /www.ncbi.nlm.nih. gov/pubmed/9651890>. Acesso em: 22 maio 2016.

MOHAMMED, Fihri; ABDALAZIZ, Safa; BASHER, Haifa; TARIQ, Saleem. Determination of weight distribution in the foot. International Conference on Computing, Electrical and Electronics Engineering (ICCEEE), IEEE, 2013, p. 434 436. Disponível em:<http:/ /ieeexplore.ieee.org/xpls/abs_all. jsp?arnumber=6633977>Acesso em: 4 jun. 2016.

MURO DE LA HERRAN, Alvaro; GARCÍA ZAPIRAIN, Begoña; MÉNDEZ ZORRILLA, Amaia. Gait Analysis Methods: An Overview of Wearable and Non Wearable Systems, Highlighting Clinical Applications. Sensors, v. 14, n. 2, p. 3362 3394, 2014. Disponível em: <http:/ / www.mdpi.com/1424 8220/14/2/3362/>. Acesso em: 16 mar. 2016.

NOVEL - PRODUCT INFO - PRICES - EMED. Disponível em: <http:/ / www.novel. de/old/productinfo/prices-emed.htm>. Acesso em: 5 jun. 2016.

NOVEL - PRODUCT INFO - PRICES - PEDAR. Disponível em: <http:/ / www.novel. de/old/productinfo/prices-pedar.htm>. Acesso em: 5 jun. 2016.

RAZAK, Abdul H.; ZAYEGH, Aladin; BEGG, Rezaul K.; WAHAB, Yufridin. Foot Plantar Pressure Measurement System: A Review. Sensors, v. 12, n. 12, p. 9884 9912, 2012. Disponível em: <http:/ / www.mdpi.com/1424 8220/12/7/9884/>. Acesso em: 16 mar. 2016.

SAZONOV, Edward S; FULK, George; HILL, James; SCHUTZ, Yves; BROWNING, Raymond. Monitoring of Posture Allocations and Activities by a Shoe Based Wearable Sensor. IEEE Transactions on Biomedical Engineering, v. 58, n. 4, p. 983 
990, 2011. Disponível em: <http:/ / ieeexplore.ieee.org/lpdocs/epic03/wrapper. htm?arnumber=5447796>. Acesso em: 16 mar. 2016.

SHU, Lin; HUA, Tao; WANG, Yangyong; LI, Qiao; FENG, David D. In Shoe Plantar Pressure Measurement and Analysis System Based on Fabric Pressure Sensing Array. IEEE Transactions on Information Technology in Biomedicine, v. 14, n. 3, p. 767 775, 2010. Disponível em: <http:/ / ieeexplore.ieee.org/lpdocs/epic03/wrapper. htm?arnumber=5378500>. Acesso em: 16 mar. 2016.

TANWAR, Hitika; NGUYEN, Lim; STERGIOU, Nicholas. Force Sensitive Resistor (FSR) based Wireless Gait Analysis Device. The Third IASTED International Conference on Telehealth, ACTA Press, 2007, p. 1 6. Disponível em: <http://dl.acm. org/citation.cfm?id=1672136.1672138> . Acesso em: 22 maio 2016.

TAO, Weijun; LIU, Tao; ZHENG, Rencheng; FENG, Hutian. Gait Analysis Using Wearable Sensors. Sensors, v. 12, n. 12, p. 2255 2283, 2012. Disponível em: <http:/ / www.mdpi.com/1424-8220/12/2/2255/>. Acesso em: 16 mar. 2016.

URRY, Stephen. Plantar pressure measurement sensors. Measurement Science and Technology, v. 10, n. 1, p. R16, 1999. Disponível em: <http:/ /stacks.iop.org/0957 0233/10/i=1/a=017>. Acesso em: 22 maio 2016.

VILAR, Walter D. Química e Tecnologia dos Poliuretanos. 3a Ed, Vilar Consultoria, Rio de Janeiro, 2004. E book. Disponível em <http:/ / www.poliuretanos.com.br/ Cap4/48Calcados.htm>. Acesso em: 4 jun. 2016.

WAHAB, Yufridin; BAKAR Norantanum A. Gait analysis measurement for sport application based on ultrasonic system. 15th International Symposium on Consumer Electronics (ISCE), IEEE, 2011; p. 20 24. Disponível em: <http:/ /ieeexplore.ieee. org $/$ xpl/login.jsp?tp=\&arnumber=5973775\&url=http\%3A\%2F\%2Fieeexplore.ieee. org\%2Fxpls\%2Fabs_all.jsp\%3Farnumber\%3D5973775>. Acesso em: 3 jun. 2016. 